\title{
Child health and paediatric care in Spain: where are we going?
}

\author{
Angel Ballabriga
}

This is the fourth paper in a series showing the problems facing the medical services for children in different countries.

Biomedical Research Unit, Children's Hospital

'Vall d'Hebron', Autonomous University, Barcelona, Spain

Correspondence to: Professor Angel Ballabriga, Hospital Materno Infantil Vall d'Hebron Paseo Vall d'Hebron $\mathrm{s} / \mathrm{n}, 08035$ Barcelona, Spain.

\section{The National Health Service}

The National Health Service (NHS), providing free medical care, was initiated in 1945 to cover part of the Spanish population, and was then progressively expanded to the entire population. In 1950 the NHS incorporated paediatricians to give paediatric care to children from 0 to 8 years of age. In the 1960s great structural improvements took place, including the inauguration of five large well equipped children's hospitals. During the next 11 years the level of hospital care for children was dramatically improved, after which important changes in the administrative structure were introduced, which in our opinion have not favoured development of the paediatric service.

Since 1977, there have been important political discussions concerning the 'model of medical care' to be applied. Spain has become a so called state of autonomies, with 16 geographical areas with different degrees of independence from the political and administrative points of view, including public health care. At present, there is a mixed medical model, in which all the population is affiliated to the NHS by obligation, coexisting with the practice of private liberal medicine and medical care obtained through voluntary membership at their own cost to insurance companies. In some large geographical areas there is a total degree of administrative autonomy concerning medical care organisation, in other areas there is partial autonomy, and in others medical care depends completely on the central government Health Ministry. This causes differences in priorities and for these different reasons, sometimes even due to political prestige, some public health programmes receive more attention than others. In our opinion, this could lead in the short term to a loss of homogeneity in the distribution of medical care.

Over the last few years, criticism of the NHS has strongly increased and even the media comment on the chaotic situation of this service. Others, still more critical, use public health as a political arm to collect votes or for internal manoeuvres in political parties. Faced with this situation the administration talks about the need for decentralisation and autonomy for hospitals and health centres but this question remains for the moment as pure speculation. The Blendon survey, ${ }^{1}$ carried out recently in Spain to discover the degree of satisfaction felt by the users of the NHS, shows that $25 \%$ thought that the system should be completely changed and another $49 \%$ considered that fundamental changes should be introduced. It is very significant that even with these very negative aspects, $71 \%$ of NHS users demonstrated their approval of the quality of medical care received. Their criticism was of the organisation, efficiency, bureaucracy, and financing of the system. Now there is a confrontation of two opposite views: on one hand, the trend towards a scientific approach to the problems, supported by the majority of physicians and, on the other, the orientation to a purely economical management as first priority. This latter is represented by a new elite of economists and some young physicians acting as state bureaucrats, politically dependent on the system. Putting government economists in charge of the hospitals added a humiliating loss of control for the physicians. ${ }^{2}$

It is evident that a good financial balance should be obtained and that public health medical expenses must be controlled. However, in our opinion the solution does not lie in rigid economies but rather in the avoidance of squandering money for political gain. On the other hand, if physicians had better opportunities for continuous medical education and greater satisfaction in their work, expenses would be reduced. The fact is that although the public health budgets have multiplied threefold in the last nine years, general discontent still remains. Public health expenses as a percentage of the gross national product is 4.5 in Spain, compared with 5.3 in the UK, 6.3 in Germany, 6.7 in France, and 8.3 in Sweden. ${ }^{3}$ Recently, as a consequence of the continuous polemics about public health the Spanish parliament requested a report from a committee concerning the matter and the so called Abril report was born. ${ }^{4}$ From this report, the failure of the NHS management is clear. The expenses of medication are $20 \%$ of the total. For some this report is very pragmatic and full of common sense and for others it is cold and niggardly. Waiting lists are very long although Spain, when compared with other countries, has more physicians for the total population and an enormous number of unemployed young physicians. Some autonomous communities, such as Catalonia, try to liberate themselves from this situation with more good will than success; despite a great display of propaganda, consumers ask for a more flexible and less bureaucratic public health system, and the public health workers are dissatisfied and unmotivated. 
Development of paediatrics

In the development of Spanish paediatrics during the last five decades, three stages must be differentiated. The first was a phase of restrictions from 1945 to 1960 , after the Spanish Civil War and the second world war, with a precarious economy and international isolation and with high infant mortality and children's diseases typical of developing countries. Paediatric public health was orientated towards programmes of vaccinations, nutrition, and well baby clinics.

The second stage was a phase of expansion from 1960 to 1975 . The international isolation progressively disappeared, the economy improved, international scientific contacts became easier, and large paediatric hospitals were inaugurated. At the same time, paediatric specialties began to be developed in these hospitals and educational programmes were started at national level for residents in paediatrics; the number of faculties of medicine were increased and better facilities for research could be obtained. This was a time of great prosperity for paediatrics. Curiously, we disposed of modern equipment facilities which had been suitable to treat diseases typical of developing countries. The medical panorama had completely changed, the reduction of infant and perinatal mortality was dramatic, and the diseases common to undeveloped countries gave way to those of developed countries. There was an enormous improvement in the quality of medical care in hospitals, but less quality in primary care.

The third stage, since 1975 , is a phase of stagnation, and at times regression. Our country has passed in the course of a few decades from a semideveloped to a highly developed industrialised society, the birth rate is declining dramatically and the development of family planning is enormous. Many years ago, paediatrics officially included only children up to the age of 8 years, but now the age limit has been increased to 15 years. In the memorandum presented by the Board of the Spanish Paediatric Association to the Minister of Public Health in 1989, our association expressed concern about the scarce attention that the administration dedicates to the child. ${ }^{5}$ The investments are made too late, are uncoordinated, and are unproductive. The fact that infant mortality has decreased to satisfactory figures does not justify decreasing attention to the child. Generally, our complaints fall on deaf ears and the administration maintains an arrogant attitude and our politicians badly tolerate criticism.

The Educational programme for residents in paediatrics (MIR programme) in recent years has resulted in a considerable number of physicians obtaining a high degree of specialisation. They have occupied new positions in

Vital statistics in Spain

\begin{tabular}{lcrrrrrrrrr}
\hline & 1965 & 1970 & 1975 & 1980 & 1985 & 1986 & 1987 & 1988 & 1989 & 1990 \\
\hline Infant mortality & $37 \cdot 3$ & $25 \cdot 4$ & $18 \cdot 9$ & $12 \cdot 3$ & $8 \cdot 9$ & $9 \cdot 2$ & $9 \cdot 0$ & $8 \cdot 5$ & $7 \cdot 8$ & \\
Perinatal mortality & & $25 \cdot 4$ & $21 \cdot 1$ & $14 \cdot 5$ & $11 \cdot 0$ & $10 \cdot 7$ & & & & \\
Neonatal mortality & & & $12 \cdot 6$ & $8 \cdot 5$ & $5 \cdot 9$ & $6 \cdot 2$ & & & & \\
Birth rate & 21.1 & & $18 \cdot 8$ & $15 \cdot 2$ & $11 \cdot 8$ & $11 \cdot 2$ & $10 \cdot 8$ & $10 \cdot 7$ & $10 \cdot 4$ & $10 \cdot 26$ \\
Total population (millions) & 31.9 & & $35 \cdot 4$ & & $37 \cdot 7$ & & & & & $38 \cdot 9$ \\
\hline
\end{tabular}

All data after 1986 are provisional. health centres for primary care, resulting in a great improvement in the quality of assistance. This new paediatrics presumes a reduced number of admissions of children to hospital but who have more sophisticated problems. The administration has reacted by facing this new situation with a remarkable lack of imagination. A paediatric hospital completely ready for use was not even opened and many floors of paediatric hospitals are being converted for adult care while the opportunity is being lost of giving more attention and development to the problems of adolescence that must be included in paediatrics, together with the creation of new programmes for rehabilitation, attention to emotional disturbance, and teenage pregnancies.

\section{Vital statistics}

The infant mortality rate, perinatal mortality, neonatal mortality, birth rate per 1000 population, and total estimated population over the last decades and in recent years are shown in the table. ${ }^{6-9}$ The fertility rate in 1960 was 2.9 and in 1987 was 1.7 . The total number of paediatricians registered in Spain in 1990 was 8421 .

\section{Neonatology aspects}

Since 1960 there has been a notable decrease of perinatal and neonatal mortality, but the distribution for geographical areas is not uniform throughout Spain. ${ }^{10}$ Perinatal mortality in 1984 shows a maximum of 15.09 in the Rioja area and a minimum of $6 \cdot 14$ in Catalonia. Early neonatal mortality represents $51.6 \%$ of the total infant mortality. Social and clinical modality variables associated with perinatal mortality in Spain over a period of five years have been studied ${ }^{11}$ and an analysis made of the correlation and linear regression between perinatal mortality and socioeconomical variables such as family income, percentage of active population of the primary sector, percentage of women of fertile age with elementary or high school education, number of beds for obstetrics and neonatology, and the number of active obstetricians and paediatricians for $\mathbf{1 0 0 0}$ live births. This study showed that the maximum correlation corresponded to the disposable family income, while the number of maternal and neonatal beds per 1000 live births did not show a significant correlation. In Barcelona City, perinatal mortality in the different districts shows a rate ranging between $20 \cdot 7$ and $8 \cdot 64,,^{12}$ the difference depending on the socioeconomic condition of the families that live in certain areas, all of whom have the same free access to the medical service. More valid information is necessary concerning incidence and timing of perinatal death, to establish appropriate strategies. For this, the establishment of rapid and efficient systems for data collection is necessary. The present system is bad and delayed, and there are no banks of public health data that are sufficiently up to date for consultation. The future of neonatology in our country must include greater effort to improve the survival of very low birthweight infants. ${ }^{13}$ This particular group remains one with high rates of death and disability. Perhaps 
it is more important to obtain not only better care but better babies in women of very low income. The priorities for neonatology must include not only more money for more sophisticated units but more money for prevention and intervention programmes for families with a very low income. Likewise, an increase in health education is necessary so that pregnant women attend antenatal clinics more often.

Another important problem is neonatal transportation. The problem is not solved only with good organisation of 'newborn transfers' but with a preventive 'maternal-fetal transfer'. The Neonatology Section of the Spanish Paediatric Association has sounded a note of alarm concerning the inadequate conditions during transport of newborn infants to referral centres. Education of the public and policy makers about the importance of reducing the numbers of low birthweight babies should be emphasised. The magnitude of preventable death occurring during the neonatal period must be evaluated. This is not a call for reducing budgets for technology or stopping medical progress, but rather a call for spending more money for identifying problems where a solution requires other methods.

Low birthweight infants represent between $5 \%$ and $7 \%$ of newborns in our country. A survey including 5345 newborn infants in 16 different centres in Spain showed that the proportion of infants of low birth weight of less than $2500 \mathrm{~g}$ was $4 \cdot 87 \%$ in 1982 and $7 \cdot 17 \%$ in $1989^{14}$; of these $0.8 \%$ in 1982 corresponded to infants of less than $1500 \mathrm{~g}$ and in 1989 it was $1.42 \%$. These data show a negative trend with a progressive increase in the rate of low birth weight. If this tendency is maintained, at the end of this century we will have rates typical of a developing country. Of this group of low birthweight infants, $7 \cdot 2 \%$ of the mothers were under 20 years of age, $31 \%$ were smokers and, once aware of the pregnancy, only $14 \%$ stopped smoking. Priority should be given to antenatal clinics in the integral planning of mother and child care.

\section{Nutrition}

Data from 1965 show that the incidence of breast feeding was around $89 \%$. This decreased progressively to approximately $41.5 \%$ in 1983 before rising again to $82 \%$ in the next six years. ${ }^{15}$ The figures vary in different areas in Spain and also according to the different sociocultural levels. The average duration of breast feeding also differs, for example $2 \cdot 7$ and 3.3 months, and only $13 \%$ maintain lactation to the sixth month; $8 \cdot 38 \%$ of the mother were smokers. Early ending of breast feeding occurred more frequently in young mothers from the lower cultural and socioeconomic groups. Study of pesticides in human milk shows high concentrations but not values regarded as toxic. ${ }^{16}$ The reason most often cited for using breast milk substitutes was a decrease in the milk flow; mother's work played a part in only $6.4 \%$ of cases. ${ }^{17}$ Before 12 months of age $44 \cdot 5 \%$ of infants received fresh cows' milk and in $21 \%$ of cases complementary feeding with solids was given before 3 months of age.
The general state of nutrition of the child population in Spain at the present time can be considered as very good. Cases of malnutrition commonly existed up to the 1950 s but our society is now becoming one suffering from overnutrition. The rate of obesity in our child population has been established as $5 \cdot 8 \%$ in rural areas, and $4.8 \%$ in urban areas, and $4 \%$ in metropolitan areas. ${ }^{18} \mathrm{We}$ emphasise the existence of bad feeding habits in adolescents caused by the introduction of new life styles and high consumption of hamburgers, pizza, take away foods, and in certain groups junk diets. In at least 10 different surveys in different parts of Spain hypercholesterolaemia has been found in schoolchildren and adolescents, which was related to diets with high intake of saturated fats and cholesterol. ${ }^{19}$ In Spain an important trend of increasing height of the population has occurred throughout this century, this being particularly noticeable during the last 20 years. $^{20}$

Concerning dental caries, some local community programmes for buccal and dental health have been integrated into school schedules, and the distribution of oral fluoride solutions in health centres has been started for children between 6 months to 14 years of age. However, various studies still show dental caries in $59.6 \%$ of schoolchildren, and health education must be improved in this respect. The NHS is very deficient in providing buccal and dental care for children.

\section{Metabolic screening and congenital malformations}

The programme for prevention of congenital metabolic diseases includes 18 centres orientated to the detection of phenylketonuria and hypothyroidism in newborn infants. The incidence found is $1 / 26526$ for phenylketonuria, $1 / 17684$ for hyperphenylalinaemia, and $1 / 2500$ for hypothyroidism. ${ }^{21}$ Some of these centres also work with a programme of detection of 21hydroxylase deficiency, which has an incidence of $1 / 12379$ for homozygotes. The percentage of false positives was $1 \cdot 7 \%$.

As regards cystic fibrosis the $\Delta$ F508 mutation accounts for only a small part of the total range of cystic fibrosis defects in Spain. In southern Europe the $\Delta$ F508 mutation is $52.9 \%$ compared with $75.6 \%$ in northern Europe, which means that between $25 \%$ and $50 \%$ of couples will still need to undergo tests with the marker closely linked to the cystic fibrosis gene, as they do not have the $\Delta$ F508 mutation. ${ }^{22}$

The Spanish collaborative study performed between 1976 and 1985 on 551902 newborn infants showed 11099 congenital defects. ${ }^{23}$ For every 1000 live births the proportion with congenital dislocation of the hip was $4 \cdot 1$, for foot deformities $2 \cdot 18$, for hypospadias $1 \cdot 84$, for Down's syndrome $1 \cdot 5$, and for spina bifida $0 \cdot 42$. Since 1984 the alcoholic fetal encephalopathy syndrome has also been included in the list, with an incidence of 0.17 for every 100000 .

\section{Health centres}

Recently, many of the outpatient paediatric 
consultations have been transferred to health centres in which there is a coordinated team giving primary care with a high level of coordination between hospitals and health centres. The idea is to work with less bureaucracy and more flexibility, giving primary paediatric care together with preventive aspects and rehabilitation in combination with social services. The aim of the health centre is also to avoid the physician's feeling of frustration faced with routine and to study environmental conditions with the intention of introducing intervention programmes. In this way integral paediatrics is established in a limited geographical area. These centres can also be useful for the training of resident physicians working in large hospitals.

\section{Infectious diseases and vaccination}

The pattern of infectious diseases in Spain has changed substantially during the last three decades. Prevalent diseases before the 1960s such as diphtheria and poliomyelitis have disappeared thanks to vaccination programmes. Measles is strongly declining and also tuberculosis. A cross sectional survey in the city of Barcelona on immunisation coverage of 2 year old children in 1988 demonstrated that vaccination coverage was $93 \cdot 1 \%$ for measles, $92 \cdot 0 \%$ for mumps, and $91 \cdot 2 \%$ for rubella. Up to $91 \cdot 2 \%$ of children have received four doses of polio vaccine, and $91.6 \%$ have received four doses of the combined diphtheria, tetanus, and pertussis vaccine. ${ }^{24}$ The degree of the mother's education is closely correlated with the level of vaccine coverage. The general target is to achieve $93 \%$ of coverage for all vaccines in children between 4 and 6 years old for 1995 , and reach $97 \%$ for the year $2000 .^{25}$

Meningococcal infection is endemic but the rates are dropping, in 1983-5 the rate was 8.85/ 100000 inhabitants, and in 1990 it was 3.04 . Of these, $78 \%$ of cases correspond to patients of less than 15 years of age. Meningococcal typing shows that $81-85 \%$ correspond to group $B$ and $14 \cdot 1 \%$ to group C. Penicillin resistant strains have been isolated in 13 provinces and $0.3 \%$ of the strains studied was resistant to rifampicin. ${ }^{26}$

In neonatal meningitis there is a predominance of streptococcus B, Escherichia coli, and listeria. Gastrointestinal infections have changed with a decrease of $E$ coli infections and an increase of infections by salmonella, campylobacter, rotavirus, yersinia, and cryptosporidium. Visceral leishmaniasis has decreased and now in certain areas has a rate of $2 \cdot 12$ cases $/ 100000$ inhabitants, the high risk group being children between 0 and 4 years of age. This infection is related with the existence of canine leishmaniasis with rates of 1.6 to $15 \%$ in dogs according to different areas. Boutonneuse fever caused by Rickettsia conorii a prevalent disease in Mediterranean areas, is observed in our children but not often. ${ }^{27}$

Two very important problems concerning infectious disease in children are hepatitis and AIDS. A study of hepatitis markers in the school population in Catalonia shows that the incidence for hepatitis B surface antigen (HBsAg) and hepatitis B surface antibody in children between 6 and 14 years was 0.4 and 0.8 respectively and the incidence increases between 15 and 24 years to rates of 1.7 and 9.3 respectively, demonstrating that infection is mainly acquired during adolescence. In this area, a selective programme of vaccination directed to adolescents and high risk groups, including newborns of $\mathrm{HBsAg}$ positive mothers, has been developed. ${ }^{25}$ Concerning AIDS, a survey comprising 83 paediatric centres carried out between 1981 and 1989 reported 1938 cases of HIV positive infants born to HIV positive mothers. ${ }^{28}$ Of these cases, $33.3 \%$ were from Madrid and $24 \cdot 2 \%$ from Catalonia. This study has demonstrated that at this moment the number of HIV positive infants born to positive mothers is higher in Spain than the total cases from six other European countries together. Infants contaminated by transfusions and haemophilic children have been excluded from these statistics. The rate of infection of these 1938 cases at 18 months of age was $25.6 \%$ and in this group $55 \%$ already had clinical symptoms. Of the mothers, $93 \%$ were parenteral drug abusers and $33 \%$ of these babies were of low birth weight. We see an incidence of one HIV positive newborn/ 1000 deliveries, but our survey included only public hospitals; as $35 \%$ of deliveries take place in private clinics, the figures of the survey represent only the tip of the iceberg. We need the development of adequate multidisciplinary units to follow up these children. On the other hand, HIV positive neonates are one of the most discriminated and unprotected groups of our society because they are not being openly supported by the respective HIV pressure groups. ${ }^{29}$ For this reason, it is necessary that health authorities, the mass media, and the general public combat this discrimination and compensate for the absence of a pressure group for children.

\section{Accidents in childhood}

Accidents represent $20 \%$ of emergencies in children's hospitals in our country and $25 \%$ of admissions to paediatric intensive care units. If neonatology is excluded, accidents correspond to $13 \%$ of all admissions in our paediatric hospitals. Blows and falls constituted $76 \cdot 1 \%$ of accidents in a survey of 5021 cases. The main incidence is between 0 and 4 years of age and the accidents are usually at home, particularly in the kitchen. Traffic accidents, however, are the main cause of accidental death in childhood, the greatest incidence being in the groups of 5-9 and $10-14$ years. ${ }^{30}$ Intoxication and burns are more frequent between 1 and 4 years.

\section{Transplantation in children}

The law that established regulations for transplantation in our country was passed in 1979. Terminal renal failure in children has a rate of 5.2 per million children a year. For the development of the kidney transplantation programme, Spain covers five different geographical areas, each area including 5-8 million inhabitants, and a further area covering the Canary Islands. Children's kidney transplantations are performed in the surgical departments of paediatric 
hospitals. Up to 1989 there have been 77 paediatric liver transplantations performed in three centres with survival rates similar to other European series. There are also special units for bone marrow transplantation in children.

\section{Teenage problems}

At present, adolescents are not officially integrated into paediatric hospitals but in recent years adolescence has progressively become part of the paediatric education programme and in some hospitals we have started its incorporation in paediatrics. The increasing presence of problems such as teenage pregnancy, drug addiction, nutritional problems related to life styles, and sexually transmissable diseases in early adolescence make it necessary. Alcohol consumption is a very important problem in our country and different studies show that between $56.6 \%$ and $71 \cdot 6 \%$ of students drink alcohol. ${ }^{31}$ In another study, $89 \%$ of teenagers were beer drinkers and $92 \cdot 1 \%$ said they had no problems about buying alcohol, ${ }^{30}$ although the law does not allow it at this age. The incidence of alcohol consumption was higher in groups of low socioeconomic status, particularly in children of unskilled workers. There is a close statistical correlation between smoking and alcohol consumption. ${ }^{32}$ Regarding the habit of smoking, a study in teenagers demonstrated that at 10 years of age it was of $9 \%$ and at 18 years it had risen to $63 \% .^{33}$ In our country, from $1957-80$ sales of cigarettes increased by $150 \%$ while in the same period the population had only increased by $22 \%$. The study of 25130 children between 12 and 18 years in Cadiz showed that $25 \%$ smoked in the street and $21 \%$ smoked in school, although it is prohibited there. ${ }^{34}$ Although the prevention campaigns have intensified, we should not forget that both tobacco and alcohol are good sources of income for the government. Consumption of psychoactive drugs is a key problem in public health in Spain. The trafficking of drugs in Spain is punished by law but personal consumption is not. At present there are even public demonstrations against drugs. In young mothers drug abuse has played the main part as the mechanism of AIDS transmission. The average age for starting heroin is 18 years but earlier cases, around the age of 10, are not uncommon and the age for starting inhaled solvents is 8 years. ${ }^{35}$ Cannabis smoked with tobacco is the most frequent addiction. Cocaine consumption occurred in $3 \%$ of youngsters between 16 and 20 years in 1989. The main problem is the subsequent behaviour that is caused by drug addiction.

\section{Training in paediatrics}

The national programme to obtain the certificate of specialist in paediatrics demands training as a resident in an accredited paediatric department for four years, during which period there is remuneration. This programme was started in 1966. The number of candidates trying to obtain a position on this programme is usually from six to 10 for each available place. In 1991 there were 3701 positions for all specialties inside this programme, of which $25 \%$ were dedicated to family medicine and $215(5 \cdot 8 \%)$ were devoted to paediatrics. The selection takes place at a national level, through a multiple choice test. In our opinion this method is full of problems and does not allow for an adequate selection of candidates as there is no information about the skills of communication and there is no personal interview of the candidate. ${ }^{36}$ On the other hand, we believe that the current restriction in specialisation makes no sense; if this has to be made, it should be at the beginning of studies not at the end. Even with the problems of the programme, it has been more useful than previous schemes and has provided well trained paediatricians. At present there is no official recognition of subspecialties in paediatrics except for paediatric surgery, for which the training is five years. Of course, during the residents' programmes there is rotation that takes in the different subspecialities and in many cases the final two years allow greater attention to a certain subspecialty.

In a prospective study concerning medical practice published in 1980 a group of experts stated in relation to medical research that 'the research is very interesting, a high number of professionals are interested, it is badly paid work and practically non-existent' ${ }^{37}$ Preliminary drafts of the report indicated that Spanish medicine, of course including paediatrics, would in $\mathbf{1 0}$ years have a structure with the same style as that of the more advanced Western countries. Unfortunately, I am of the opinion that this statement has not been confirmed, although certain facilities are now possible with grants obtained through official research programmes.

\section{Where are we going?}

In spite of the strong criticism we make about the system, the progress in the development of paediatrics in our country over the last 25 years has been enormous and the contribution of our paediatricians has been more than generous and efficient. It has not, however, been possible to achieve all the goals initially proposed and it would be desirable that our administration, both central and autonomous, be less arrogant, less dogmatic, less bureaucratic, more flexible, more ready to accept criticism, and more cooperative with professionals who still maintain a pure scientific spirit. In this way it would be possible to establish and discuss a balance between finance, salaries, expenses, management, scientific perspectives and priorities and so allow for good progress in a not too far distant future. Priorities are always a very delicate subject. It is evident that high technology must be developed, but one should not be dazzled by it, and at the same time basic paediatric services should be homogeneous throughout the country.

Government expenditure on public health has notably increased over recent years, but this is still not enough for good paediatrics and to include prevention programmes. More financial support is needed and for this perhaps other sources of finance are necessary. The increase of 
public expenditure in Spain is enormous and important allocations of the government's budget go to trade unions, political parties, and bureaucracy. Perhaps it is there where restrictions should be made, as tax capacity has already been saturated.

In spite of all of this, we still feel happy! Because for the moment when we are sick we can go to our NHS doctor. Perhaps in a near future we will be obliged to go first to our NHS economist!

1 González G. La encuesta Blendon. Noticias Medicas 1991; 3441:10-2.

2 Drane JF. Spanish medicine: trying to heal itself? Letter from Madrid. $\mathcal{F A M A}$ 1988;260:1219-20.

3 OCDE en chiffres. Statistiques sur les pays membres. Edition supplément a l'observateur de l'OCDE, 158, juin-juillet, 1989. (Quoted from Els recursos economics del Department de Sanitat i Seguretat Social, Generalitat de Catalunya, Departament de Sanitat i Seguretat Social, Barcelona, 1991.

4 Informe Comisión Abril. Noticias Médicas 1991;3441:26-30. emorandum que la comisión ejecutiva de la Asociación Española de Pediatriá presentó al Excmo Sr Ministro de Sanidad y Consumo con ocasión de la audiencia que tuvo lugar el 5 de mayor de 1989. An Esp Pediatr 1989;30:512-4.

6 Instituto Nacional Estadistica. Movimiento Natural de la Población Española 1975-1986: Instituto Nacional Estadistia, 1990

7 Redondo JL, Gutierrez JL. Mortalidad infantil en Espana. Boletin Epidemiologico Semanal 1990;1875.

8 Saito $\mathrm{L}$, Kobayashi N, eds. Current status of world's children. Tokyo: N Kobayashi, 1989.

9 United Nations. Statistical papers: population and vital statistics reports. New York: United Nations, 1988. (Series $A$, vol 40 .

10 Mortalidad infantil en España. Boletin epidemiológico semanal. Madrid: Ministerio de Sanidad y Consumo. Dirección General de Salud Pública, 1985:1675.

11 Salleras L, Sentis J, Canela J, Garcia A. Facteurs sociaux et assistance sanitaire et mortalite perinatal en Espagne. Rev Epidemiol Santé Publique 1988;36:30-5.

12 Anonymous. Informe sobre la mortalitat perinatal a la ciutat de Barcelona durant l'any 1986. Servei d'Epidemiologia i estadistiques vitals. Ajuntament de Barcelona. Barcelona: estadistiques vitals. Ajuntament de Ba

13 Ballabriga A. Pediatric care: which future? Relationship amongst structures, territory and society. Spanish experience. In: Caramia G, ed. Proceedings, Bambino: progetto salute le nuove frontiere della neonatologia Europea. Ancona, Italy, 1990:93-8.

14 Canosa C, Morcillo F, Duart JM, Escrivá F, Fernández C, Muñoz A. España bajo peso al nacimiento. In: Brines J, Monleón J, eds. Proceedings XII reunion nacional de medicina perinatal. Valencia: Servicio de publicaciones PULEVA, 1990:139-48.

15 Cobaleda A, Hidalgo M, Plaza I, et al. Prevalencia de la lactancia materna y su relación con los factores de riesgo cardiovascular en la población pediátrica de Fuenlabrada. An Esp Pediatr 1989;31:350-5.

16 Conde $\mathrm{C}$. Compuestos organoclorados en leche humana. Endocrologia 1989;36:62-4.

17 Ballabriga A, Schmidt E. Actual trends of the diversification of infant feeding in industrialized countries in Europe. In: Ballabriga A, Rey J. Weaning, why, what and when? New York: Raven Press, 1987:129-51.

18 Paidos '84. Estudio epidemiológico sobre nutricion y obesidad infantil. Madrid: Graficas Jomagar, 1985.

19 Ballabriga A. Estilo de vida, medio ambiente y enfermedades en la infancia. An Esp Pediatr 1990;33(suppl 42):1-19.

20 Tojo R. Evolución del crecimiento, maduración y desarrollo humano en Galicia y España, 1900-1985. In: Pombo M, ed. Endocrinologia pediátrica. Madrid: Ediciones Diaz de Santos, 1990:105-75.

21 Anonymous. Datos analíticos correspondientes a 1990 sobre detección precoz neonatal de metabolopatias e hipotiroidismo congenito. Madrid: Prevención, 1990.

22 Estivill X. Molecular genetics of cystic fibrosis. Annales Nestlé 1991;49:23-37.

23 Estudio colaborativo Español de Malformaciones Congenitas. Malformaciones congenitas en España 1976-1985. Boletin Epidemiol Semanal 1987:1786.

24 Villalbi JR, Grauges MD. Cobertura vacunal a los dos años de edad: un estudio transversal en la ciudad de Barcelona. An Esp Pediatr 1990;32:321-4.

25 Departament de Sanitat i Seguretat Social. Document marc per a l'elaboración del Pla de Salut de Catalunya. Barcelona: Departament de Sanitat i Seguretat Social, 1991.

26 Anonymous. Vigilancia de la infección meningocócica en España. Bol Epidemiol Semanal 1991;1882.

27 Moraga A, Martinez-Roig A, Alonso JL, Boronat M, Domingo F. Boutonneuse fever. Arch Dis Child 1982;57: 149-51.

28 Canosa C, Delgado A, Garcia F, Llorens J, Omeñaca F, Ruiz J. Infección for el virus de la inmunodeficiencia humana. Encuesta multicéntrica española. An Esp Pediatr 1991;34:425-35.

29 Canosa CA. HIV infection in children. AIDS Care 1991;3: 303-9.

30 Departament de Sanitat i Seguretat Social. Consell assessor sobre accidents en la infancia. Accidents infantils a Catalunya. Estudi pilot de la morbiditat hospitalaria. Barcelona: Department de Sanitat i Seguretat Social, 1989.

31 Lopez F, Couselo J, Fernández J, Carballeira C. Hábitos de consumo de alcohol entre la población infantil gallega. An Esp Pediatr 1985;23:573-8.

32 Santo-Domingo J. Problemas relacionados con el alcohol en niños y adolescentes. An Esp Pediatr 1990;32:251-4.

33 Muñoz MT, Plaza I, Madero R, et al. Estudio de Fuenlabrada: hábito tabáquico en niños y adolescentes. Influencia brada: habito tabaquico en niños y adolescentes. Influencia sobre las variables de
Pediatr 1989;31:331-5.

34 Almenara J, Ruiz M, Rodriguez A, Abellan M, Martinez J, Fernandez J. El hábito del tabaco en población juvenil gaditana. An Esp Pediatr 1990;32:333-5.

35 Gonzalez Hachero J, Garcia R, Arguelles E. El niño adolescente y drogadicto. Perspectiva pediátrica. An Esp Pediatr 1990;32:242-7.

36 Ballabriga A. Pediatric education for specialists: critical analysis of the present health teaching system. In: Canosa CA, Vaughan VC III, Hung-Chi Lue, eds. Changing needs in pediatric education. New York: Raven Press, 1990:81-95.

37 Anonymous. Estudio prospectivo de la profesión de médico en España en la década de los 80 . Sever-Cuesta, Valladolid: Banco de Santander, 1980. 